\title{
EFFECT OF PULSED SUBSTRATE BIASING ON MACROPARTICLE IN VACUUM ARC
}

\author{
E.V. Romashchenko, A.A. Bizyukov, I.O. Girka \\ V.N. Karazin Kharkiv National University, Kharkiv, Ukraine \\ E-mail: ev.romashchenko@gmail.com
}

An analytical model of the interaction of macroparticle (MP) with vacuum arc plasma in plasma immersion ion implantation (PIII) is presented. The proposed model is based on combination of the theory of charge dynamics of MP and sheath model for PIII. In the framework of this model, the MP charge dynamics during voltage pulse as well as during interval between pulses is investigated. It is obtained that MP charge and MP behavior depend on pulsed bias parameters such as pulse duration, duty cycle and bias amplitude. It is shown that pulsed substrate biasing is effective method to control of the MPs in plasma processing.

PACS: 52.40.Hf

\section{INTRODUCTION}

Vacuum arc has been known to provide a means of producing metal plasma for thin film deposition and ion implantation $[1,2]$. The favorable characteristic features of the vacuum arc metal plasma are the high ion flux, high ionization degree, and multiple ion charge [3 - 5]. Ion bombardment of a substrate surface changes the physical, electrical, and chemical properties of the material surface.

Substrate biasing is an established technique to control the ion bombardment energy. The amplitude of the bias is a key parameter, which defines the regimes of vacuum arc discharge. Besides, the bias is often pulsed in a number of plasma processing, for example, in plasma immersion ion implantation (PIII). The typical bias in PIII is in the range 1 to $100 \mathrm{kV}$, with the lower values for semiconductor applications and higher values for metallurgical applications [2]. In PIII process, an ion beams are accelerated by electric field of the sheath to high kinetic energies that allow to them to penetrate deeply under the surface, to change the atomic composition and structure near-surface region of the target material, and, thereby, to change the properties of the material surface [6].

In spite of the above-mentioned advantages of vacuum arc, the emission of macroparticles (MPs) from the cathode spot substantially limits the wide application of vacuum arc plasma [7]. The incorporation of MPs into the coating degrades the quality of the films, e.g. produces surface roughening, protuberances, bumps and pinholes.

The observations [ 8 - 11] reveal that the application of repetitively pulsed negative bias to the substrate immersed in vacuum arc plasma can result in a substantial reduction in the number of MP inclusions in coatings.

We have recently considered the application of negative DC biasing for the decreasing of MP contamination in vacuum arc deposition $[12,13]$. The proposed model was based on combination of MP charging model and steady-state sheath model.

In the present work, we investigate the effect pulsed substrate biasing on MP contamination in vacuum arc. An analytical model of the interaction of MP with vacuum arc plasma in PIII is derived with taking into account time-varying sheath.

\section{SHEATH MODEL}

We consider a widely used Lieberman's model [14] for the sheath implantation in the planar geometry. At time $t=0$, a negative voltage pulse of amplitude $-V_{0}$ and pulse duration $t_{p}$ with zero rise and fall times is applied to the substrate immersed in uniform plasma of density $n_{0}$.

When a high voltage pulse is applied, the electrons are driven away from the substrate region on a time scale of inverse electron plasma frequency $\omega_{p e}{ }^{-1}$. This is time very short of about few nanoseconds. This leads, in turn, to creation of a region of positive space charge known as the ion matrix sheath. Then, on the slower time scale of the order of inverse ion plasma frequency $\omega_{p i}{ }^{-1}$, the ions are accelerated toward the substrate by the electric field inside the sheath and the ion current density reaches a maximum. Subsequently, the sheath edge expands outwards uncovering more ions until the end of the voltage pulse. The ion matrix sheath evolves into a quasistatic Child law sheath with time-varying current density [6]

$$
J_{C}=\frac{4}{9} \varepsilon_{0}\left(\frac{2 e}{m_{i}}\right)^{1 / 2} \frac{V_{0}^{3 / 2}}{s(t)^{2}},
$$

where $s$ is the sheath thickness, $m_{i}$ is the ion mass, $\varepsilon_{0}$ is the permittivity constant, $e$ is the elementary charge.

The sheath expansion velocity $s(t)$ is given by

$$
s(t)=s_{0}\left(1+\frac{2}{3} \omega_{p i} t\right)^{1 / 3},
$$

where

$$
s_{0}=\left(\frac{2 \varepsilon_{0} V_{0}}{e n_{0}}\right)^{1 / 2}
$$

is the matrix sheath thickness, and the ion plasma frequency $\omega_{p i}=\left(e^{2} n_{0} / \varepsilon_{0} m_{i}\right)^{1 / 2}$ can be written in terms of matrix sheath thickness and characteristic ion velocity as

$$
\omega_{p i}=\frac{u_{0}}{s_{0}},
$$

where the characteristic ion velocity is

$$
u_{0}=\left(\frac{2 e V_{0}}{m_{i}}\right)^{1 / 2} \text {. }
$$

For very long pulses (typically tens of $\omega_{p i}{ }^{-1}$ ), the stationary Child law sheath will form. The steady-state 
Child law thickness, which is the maximum sheath thickness that can be reached, is [6]

$$
s_{\max }=s_{0}\left(\frac{2 u_{0}}{9 u_{B}}\right)^{1 / 2},
$$

where $u_{B}=\left(T_{e} / m_{i}\right)^{1 / 2}$ is the Bohm velocity.

Substituting (2) into (1) yields the implantation current density

$$
J_{C}=\frac{2}{9} \frac{e n_{0} u_{0}}{\left(1+\frac{2}{3} \omega_{p i} t\right)^{2 / 3}} .
$$

The expression for sheath thickness (2) and implantation current density (7) can be made dimensionless introducing the following variables

$$
S=\frac{s}{s_{0}}, \quad J=\frac{J_{C}}{e n_{0} u_{0}}, \quad T=\omega_{p i} t .
$$

The normalized sheath thickness (2) and implantation current density (7) become

$$
\begin{gathered}
S=\left(1+\frac{2}{3} T\right)^{1 / 3}, \\
J=\frac{2}{9}\left(1+\frac{2}{3} T\right)^{-2 / 3} .
\end{gathered}
$$
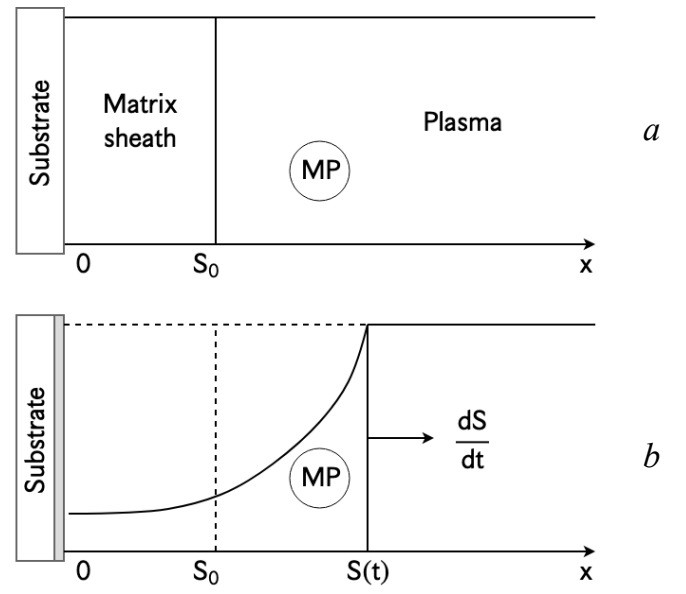

Fig. 1. Model for the plasma sheath with MP: matrix sheath (a); quasistatic Child law sheath (b)

\section{MP CHARGE DYNAMICS AND MP MOTION}

We will start our consideration of the features of MP behavior, when an ion matrix sheath is established, and neglect the time before. This assumption is valid because of the duration of negative pulses is usually much longer than $\omega_{p i}^{-1}$, and Child law sheath implantation contributes major part of the implantation process. Therefore, we can consider the interaction of MP with Child law sheath. The position of the substrate is taken to be $x=0$. The directed ion velocities are much greater than the MP velocity [4]. Thus, the MP with the radius $a$ is assumed to be at rest at point $x=x_{0}, x_{0}>s_{0}$, outside of the ion matrix sheath, as shown in Fig. 1,a. At $t=0$, MP have a negative charge $Q_{0}$ due to a difference in mobility between the electrons and ions. The sheath edge moves away from the substrate and reaches MP at the time

$$
T_{s}=\frac{3}{2}\left(\frac{x_{0}}{s_{0}}\right)^{3}-\frac{3}{2} .
$$

When MP appears in the sheath, it will be recharged due to absence of electrons which are repelled from the substrate region.

To find the recharging time for a negatively charged MP we assume that MP is recharged only by the collection of the ions. The dynamical equation of recharging is

$$
\frac{d Q}{d t}=I_{i}, \quad Q(t=0)=Q_{0},
$$

where $Q$ is the MP charge, $I_{i}$ is the ion current flowing onto MP surface.

We calculate the ion current $I_{i}$ by using the orbital motion limited (OML) approach [15]:

$$
I_{i}=\pi a^{2} \operatorname{Jen}_{0} u_{0}\left(1-\frac{e Q}{4 \pi \varepsilon_{0} a E_{i}}\right),
$$

where the normalized time-varying implantation current density $J$ is given by (10). The energy of implanted ions is [2]

$$
E_{i}=V_{0}\left[1-\left(1-\frac{x_{0}}{s_{T}}\right)^{5 / 3}\right],
$$

where $s_{T}$ is the position of the sheath when the pulse is shut off.

The position of the sheath $s_{T}$ can be obtained from

$$
\frac{3}{2}\left[\left(\frac{s_{T}}{s_{0}}\right)^{3}-1\right]=T .
$$

The OML approach is applicable if the MP radius is much smaller than the Debye length $\lambda_{D}=\left(\varepsilon_{0} T_{e} / n_{0} e^{2}\right)^{1 / 2}$, where $T_{e}$ is the electron temperature.

When the pulse is shut off, the sheath is collapsed, and MP remains behind. As a result, two ways of MP behavior are possible. If the MP recharging time is shorter than the pulse duration, MP remains negatively charged. And, vice versa, the MP sign changes on opposite, when the MP recharging time is longer than the pulse duration.

The energy conservation law for MP is

$$
\frac{M V^{2}}{2}=Q_{T} \varphi\left(x_{0}\right),
$$

where $M$ and $V$ are the mass and velocity of MP, respectively; $Q_{T}$ is the charge at the end of the voltage pulse, when $t=t_{p}$.

The sheath potential $\varphi\left(x_{0}\right)$ at point $x=x_{0}$, at moment $t=t_{p}$ is given by [6]

$$
\varphi\left(x_{0}\right)=-V_{0}\left(1-\frac{x_{0}}{s}\right)^{4 / 3} .
$$

In the case of positively charged MP, MP motion cannot occur according to (15). However, MP remains positively charged at very short time and, then, it will be again charged to negative charge by collection electron and ions from the plasma. The charging of MP is governed by equation

$$
\frac{d Q}{d t}=I_{i}+I_{e},
$$

where $I_{e}$ is the electron current. 
First, the MP will be lose its positive charge, and, in this case, the electron current is given by [16]

$$
I_{e}=-\pi a^{2} e n_{0} \sqrt{\frac{8 T_{e}}{\pi m_{e}}}\left(1+\frac{e Q}{4 \pi \varepsilon_{0} a T_{e}}\right), Q>0 .
$$

Then, the MP becomes negatively charged, and

$$
I_{e}=-\pi a^{2} e n_{0} \sqrt{\frac{8 T_{e}}{\pi m_{e}}} \exp \left(\frac{e Q}{4 \pi \varepsilon_{0} a T_{e}}\right), Q<0 \text {. }
$$

The steady-state negative charge is established, when the currents are balanced

$$
I_{i}+I_{e}=0 \text {. }
$$

The charging time $\tau$ is given by [17]

$$
\tau=K \frac{\sqrt{T_{e}}}{a n_{0}}
$$

where coefficient $K$ is a function of $T_{i} / T_{e}$ and $m_{i} / m_{e}$. As $\tau$ is inversely proportional to MP radius $a$, the fastest charging occurs for large particles.

In the case of negatively charged MP, MP can reach the substrate between pulses, if it will have enough energy.

\section{RESULTS AND DISCUSSION}

The numerical calculations are carried out for titanium implant ions. The specific parameters are taken as typical values from experiments: the pulse duration $t_{p}=1 \ldots 5 \mu \mathrm{s}$, the voltage pulses of amplitudes $-2 \mathrm{kV}$, $-5 \mathrm{kV},-10 \mathrm{kV}$; the plasma density is $n_{0}=10^{16} \mathrm{~m}^{-3}$, the electron temperature is $T_{e}=1 \mathrm{eV}$. For these parameters the sheath thickness $s$ is obtained from expression (9). The sheath thickness $s$ is independent of the ion mass, and is proportional to the square root of the substrate bias. This is illustrated in Fig. 2. The maximum sheath thickness is of order of few centimeters, which is larger than the matrix sheath by a factor of order $\left(V_{0} / T_{e}\right)^{1 / 4}$. For substrate bias $-10 \mathrm{kV}$, the Child law sheath thickness is larger than the matrix sheath thickness in ten times.

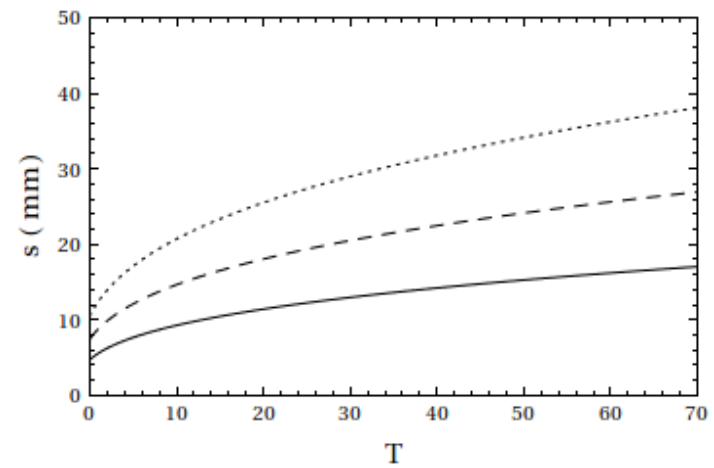

Fig. 2. Sheath thickness as function of normalized time $T$ for different substrate bias amplitude: $-2 \mathrm{kV}$ (solid line); -5 kV(dashed line); $-10 k V$ (dotted line)

The results of numerical calculations of the dynamics of recharging of a titanium MP with radius $a=0.1 \mu \mathrm{m}$, which has initially a negative steady-state charge $Q_{0}=-1 \times 10^{3} e$, are presented in Fig. 3. For titanium plasma we obtain $\omega_{p i}{ }^{-1}=50 \mathrm{~ns}$, and $T=20$ corresponds to pulse length $1 \mu \mathrm{s}$. As one can see from the Fig. 3, for the pulse duration $t_{p}=1 \mu \mathrm{s}$, in case of sub- strate bias amplitude $-10 \mathrm{kV}$, MP changes sign of charge on opposite and becomes positively charged, while, for negative pulse voltage amplitudes $-2 \mathrm{kV},-5 \mathrm{kV}$, MP remains negatively charged. The increasing of substrate bias voltage leads to faster recharging of MP.

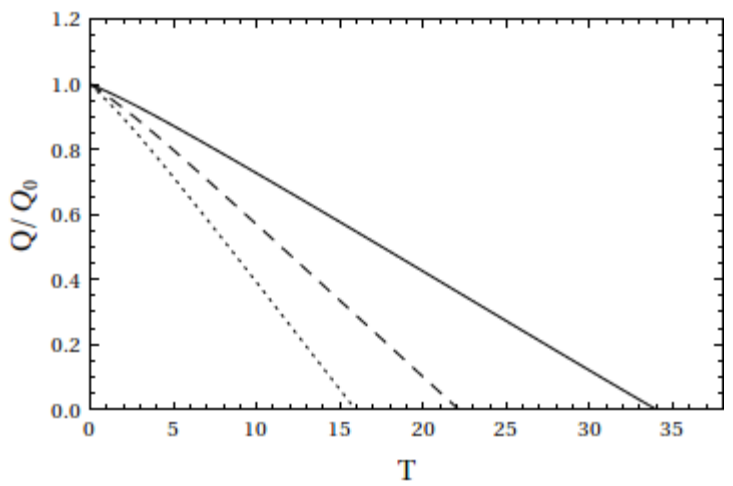

Fig. 3. Normalized MP charge as function of normalized time T for different substrate bias amplitude: $-2 \mathrm{kV}$ (solid line); $-5 \mathrm{kV}$ (dashed line); $-10 \mathrm{kV}$ (dotted line)

\section{CONCLUSIONS}

In this paper, the Lieberman's model for the sheath implantation is combined with the theory of MP charge dynamics in order to investigate the interaction of the MP with arc plasma during applying negative high-voltage pulse to the substrate and for time between the pulses.

The proposed model qualitatively explains the MP reduction due to pulsed biasing. By repetitively applying negative high-voltage bias pulses to the substrate, MPs in PIII experience many duty cycles during its flight to the substrate. For short pulses and high frequencies MPs don't reach the substrate. The pulsed substrate biasing compared to d. c. substrate biasing is the more effective method to reduce MP contaminations of the coatings. These results agree with experimental observations.

\section{REFERENCES}

1. R.L. Boxman, P.I. Martin, and D.M. Sanders. Handbook of Vacuum Arcs Science and Technology: Fundamentals and Applications. New Jersey: "Noyes Publications", 1995, p. 737.

2. A. Anders. Handbook of Plasma Immersion Ion Implantation and Deposition. New York: "John Wiley \& Sons", 2000, p. 736.

3. I.I. Beilis. State of theory of vacuum arcs // IEEE Trans. Plasma Sci. 2001, v. 29, № 5, p. 657-670.

4. G.Yu. Yushkov. Ion velocities in vacuum arc plasmas// J. Appl. Phys. 2000, v. 88, № 10, p. 56185622.

5. A.A. Plyutto, Y.N. Ryzhkov, and A.T. Kapin. High speed plasma streams in vacuum arc // Sov. Phys. JETP. 1965, v. 20, № 2, p. 328-337.

6. M.A. Lieberman and A.J. Lichtenberg. Principles of Plasma Discharge and Material Processing. New York: "John Wiley \& Sons", 2000, p. 299.

7. R.L. Boxman, S. Goldsmith. Macroparticle contamination in cathodic arc coatings: generation, transport and control // Surf. Coat. Technol. 1992, v. 52 , p. $39-50$. 
8. M. Huang, G. Lin, Y. Zhaio, et al. Macroparticle reduction mechanism in biased arc ion plating of TiN // Surf. Coat. Technol. 2003, v. 176, p. 109-114.

9. G. Lin, Y. Zhao, H. Guo, et al. Experiments and theoretical explanation of droplet elimination phenomenon in pulsed-bias arc deposition // J. Vacuum Sci. Technol. 2004, v. 22, p. 1218-1222.

10. D.O. Sivin, A.I. Ryabchikov, A.I. Bumagina, et al. Titanium macroparticles density decreasing on the sample, immersed in plasma, at repetitively pulsed biasing // Appl. Surf. Sci. 2014, v. 310, p. 126-129.

11. A.I. Ryabchikov, P.S. Ananin, D.O. Sivin, et al. Influence of negative bias pulse parameters on accumulation of macroparticles on the substrate immersed in titanium vacuum arc plasma // Surf. Coat. Technol. 2016, v. 306 A, p. 251-256.

12. A.A. Bizyukov, I.O. Girka, E.V. Romashchenko. Transport of a macroparticle in vacuum arc sheath //
IEEE Trans. Plasma Sci. 2016, v. 44, № 7, p. 1050 1056.

13. A.A. Bizyukov, I.O. Girka, E.V. Romashchenko, O.D. Chibisov. Macroparticles in beam-plasma systems// Problems of Atomic Science and Technology. Series “Plasma Physics”. 2016, № 6, p. 187-190.

14. M.A. Lieberman. Model of plasma immersion ion implantation // J. Appl. Phys. 1989, v. 66, № 7, p. 2926-2929.

15. I. Langmuir. Collected Works of Irving Langmuir / Ed. by G. Suits. New York: "Pergamon”, 1961.

16. J. Goree. Charging of particles in a plasma // Plasma Sources Sci. Technol. 1994, v. 3, p. 400-406.

17. C. Cui and J. Goree. Fluctiations of the charge on a dust grain in a plasma // IEEE Trans. Plasma Sci. 1994, v. 22, p. 151-158.

Article received 27.05.2019

\section{ВЛИЯНИЕ ИМПУЛЬСНОГО ПОТЕНЦИАЛА ПОДКЛАДКИ НА МАКРОЧАСТИЦУ В ВАКУУМНОЙ ДУГЕ}

\section{Е.В. Ромащенко, А.А. Бизюков, И.А. Гирка}

Представлена модель взаимодействия макрочастицы (МЧ) с плазмой вакуумной дуги при плазменной иммерсионной ионной имплантации (ПИИИ). Предложенная модель основана на комбинации теории динамики заряда МЧ и модели слоя для ПИИИ. В рамках этой модели исследуется динамика заряда МЧ как во время импульса, так и в интервале между импульсами. Получено, что заряд и поведение МЧ зависят от параметров импульсного потенциала, таких как длительность импульса, период и амплитуда потенциала. Показано, что применение импульсного потенциала является эффективным методом контроля МЧ в плазменных процессах.

\section{ВПЛИВ ІМПУЛЬСНОГО ПОТЕНЦАЛУ ПІДКЛАДКИ НА МАКРОЧАСТИНКУ У ВАКУУМНІЙ ДУЗІ О.В. Ромащенко, О.А. Бізюков, І.О. Гірка}

Подано аналітичну теорії взаємодії макрочастинки (МЧ) з плазмою вакуумної дуги при плазмовій імерсійній іонній імплантації (ПІІІ). Запропонована модель базується на комбінації теорії динаміки зарядження МЧ та теорії шару для ПІІІ. У рамках цієї моделі досліджується динаміка зарядження як протягом імпульсу, так і в інтервал між імпульсами. Отримано, що заряд та поведінка МЧ залежать від параметрів імпульсного потенціалу, таких як тривалість імпульсу, період та амплітуда потенціалу. Показано, що застосування імпульсного потенціалу є ефективним методом контролю за МЧ у плазмових процесах. 